\title{
Water Decontamination Hybrid Processes Using Photocatalytic Ultrafiltration Membranes ${ }^{\dagger}$
}

\author{
Sorin Claudiu Ulinici 1,*, Gabriela Baisan 1, Grigore Vlad 1, Adriana Popa ${ }^{2}$ and Dana Toloman 2 \\ 1 I.C.P.E. BISTRITA S.A., 7 Parcului Str., 420035 Bistrita, Bistrita-Nasaud, Romania; \\ gabibaisan@icpebn.ro (G.B.); vlad@icpebn.ro (G.V.) \\ 2 National Institute for Research and Development of Isotopic and Molecular Technologies, \\ 67-103 Donat St., 400293 Cluj-Napoca, Romania; adriana.popa@itim-cj.ro (A.P.); \\ dana.toloman@itim-cj.ro (D.T.) \\ * Correspondence: sorin_ulinici@icpebn.ro \\ † Presented at the 16th International Symposium "Priorities of Chemistry for a Sustainable Development" \\ PRIOCHEM, Bucharest, Romania, 28-30 October 2020.
}

Published: 16 November 2020

\begin{abstract}
Environmental pollution is a major threat to natural ecosystems, human health, and a challenge for the scientific world to adapt to the many side effects of industrialization and development. The paper presents the results of research designed to configure innovative water depollution hybrid technologies that use advanced oxidation processes (photocatalysis) combined with membrane separation processes, with a synergistic action of degradation of organic pollutants and separation by ultrafiltration, with the special purpose of water treatment at the point of use (POU). The hybrid processes are based on the development of photocatalytic ultrafiltration membrane systems made on quasi-inert support (PVDF) that incorporate nanostructures based on carbon nanotubes (MWCNT) doped with metal oxides. The laboratory model for the evaluation of hybrid systems is presented. It incorporates the photocatalytic ultrafiltration system in an experimental reactor with automatic control and data acquisition for the analysis of scale processes. The tests performed create the premise of elaborating the design specifications of the processes and their integration in real-scale industrial technologies.
\end{abstract}

Keywords: hybrid water purification processes; ultrafiltration photocatalytic membranes; advanced oxidation processes

Acknowledgments: The authors would like to express appreciation for the financial support of Romanian Ministry of Education and Research, Operational Program Competitiveness, POC Project 18/01.09.16, SMIS Code 105533.

Publisher's Note: MDPI stays neutral with regard to jurisdictional claims in published maps and institutional affiliations.

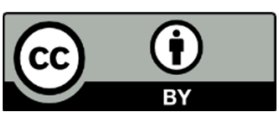

(C) 2020 by the authors. Licensee MDPI, Basel, Switzerland. This article is an open access article distributed under the terms and conditions of the Creative Commons Attribution (CC BY) license (http://creativecommons.org/licenses/by/4.0/). 